\title{
Design and Analysis of CMOS Microstrip Antenna using Matlab
}

\author{
Priyanka Saxena \\ Assistant Professor \\ ECE Department \\ MIT Moradabad
}

\author{
Prabal Bhatnagar \\ Assistant Professor \\ CSE Department \\ MIT Moradabad
}

\author{
Umesh Gupta \\ Associate Professor \\ ECE Department \\ MERI College of Engg. \& Tech
}

\begin{abstract}
The concept of microstrip antenna ${ }^{[1]}$ was first proposed by Deschamps in 1953. The microstrip antennas differ from others in a way that they radiate from a microstrip patch or a modified TEM line or slot in the ground plane. The active microstrip antenna ${ }^{[6]}$ has become prominent now a day in the field of microwave communication because of their numerous advantages such as light weight, low volume, easy fabrication, low profile and suitability for mass production.
\end{abstract}

Tremendous research and development in the field of microstrip antenna has taken place all over the world due to use in the guided weapons satellite communications and other strategic defense equipments owing to their inherent advantage over conventional microwave antennas, such as light weight, low volume and compatibility with microwave integrated circuits and solid state devices. However the major problem of microstrip antenna is their narrow bandwidth. The circular patches are probably the most extensively used which have very limited bandwidth so that it has very limited applications in the practical case. In this paper the microstrip antenna is designed which is loaded with MOS capacitance and analyze the input impedance, VSWR, reflection coefficient etc., first for unloaded circular patch microstrip antenna ${ }^{[2]}$ and then for the loaded antenna with MOS capacitor ${ }^{[3]}$.

\section{General Terms}

Antenna, Circular patch antenna, Radio Antenna

\section{Keywords}

Microstrip

\section{INTRODUCTION}

An antenna is a system of elevated conductors whish couples or matches the transmitter or receiver to free space. A transmitting antenna connected to transmit by a transmission line, forces EM waves into free space which travel in space with velocity of light. Similarly a receiving antenna connected to a radio receiver, receives a portion of EM waves travelling though space. Thus the radio antenna is defined as structure associated with the region of transition between a guided wave. According to IEEE antenna is simply defined as radiating or receiving radio waves.

In its simplest configuration a microstrip antenna consists of radiating patch on one side of a dielectric substrate ( $\leq$ 10 ), which has a ground plane on the other side. Microstrip antenna consists of very thin $\mathrm{h} \leq \lambda 0$ where $\lambda 0$ is the free space wavelength metallic strip (patch) placed a small fraction of wavelength ( $\mathrm{h} \leq \lambda 0$, usually $0.003 \lambda 0 \leq \mathrm{h} \leq 0.05$ $\lambda 0$ ) above the ground.

There are numerous substrates that can be used to design a microstrip antenna and there dielectric constants are usually in the range of $2.2 \leq \leq 12$. The ones that are most desirable for antenna performance are thick substrate where as dielectric constants in lower end of the range because they provide better efficiency larger bandwidth, loosely bound fields for radiation in the space. Ideally, the dielectric constant $\mathrm{er}$ should be low $(\sim 2.5)$, so as to enhance fringe fields which account for the radiation. The patch conductors, normally of copper and gold, can assume virtually any shape, but conventional shapes are generally used to simplify analysis and performance prediction. Often microstrip antennas are also referred to as patch antennas. The radiating elements and the feed lines are usually photo etched on the dielectric substrate. The radiating patch may be square, circular, rectangular[5], elliptical etc.

\section{MICROSTRIP ANTENNA CONFIGURATIONS}

The two most serious limitation of the microstrip antennas are narrow bandwidth and low gain. The requirement for a low volume and low profile in the antenna further deteriorates these two parameters. This is because of the fact that there is a fundamental relationship between the size, bandwidth and efficiency of an antenna. As antennas are made smaller, either the operating bandwidth or the antenna efficiency must decrease. The gain is also related to the size of the antenna, which is small antenna typically provides lower gain than larger antenna. till date, with the key design considerations such as the size reduction, together with the bandwidth and gain enhancement in wireless communication[4], many researchers have developed various techniques to enhance the bandwidth and gain of the microstrip antenna and some of the techniques are loading of high permittivity dielectric substrate, stacked configuration and slotted patch antenna[8] The use of the substrate loading technique helps to increase the radiation efficiency of microstrip antenna.

\section{DESIGN SPECIFICATION OF CIRCULAR PATCH MSA}

In The analysis of circular patch MSA is done with the following details.

\subsection{Unloaded circular patch MSA \\ Relative dielectric constant $=2.32$}

Thickness of dielectric substrate $\mathrm{h}=0.00159 \mathrm{~m}$ 
Radius of circular patch $\mathrm{a}=0.01830299 \mathrm{~m}$

Permittivity of vacuum $\varepsilon 0=8.85 * 10-12$

Feed Point of circular patch $\mathrm{r} 0=\mathrm{a} / 4.398$

Conductivity of the patch $\sigma=5.8 * 107$

Electric field $\mathrm{E} 0=1 \mathrm{~V} / \mathrm{m}$

Relative Permeability of $\mu=4 \pi * 10-7$ the substrate

Loss tangent $\delta=0.0001$

Design frequency of the patch $\mathrm{f}=3 \mathrm{GHz}$

\section{RESULTS}

\section{Observation-1}

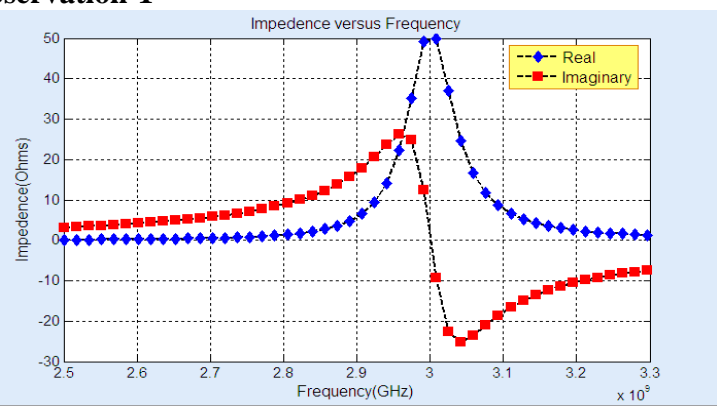

Variation of impedance vs frequency at $=2.32$

\section{Observation-2}

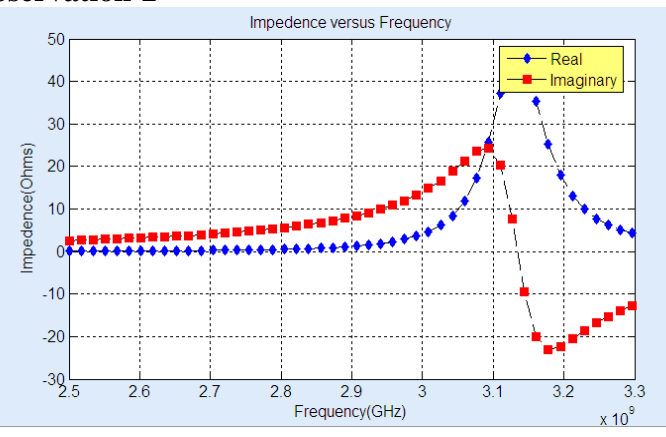

Variation of impedance vs frequency at $=2.1$

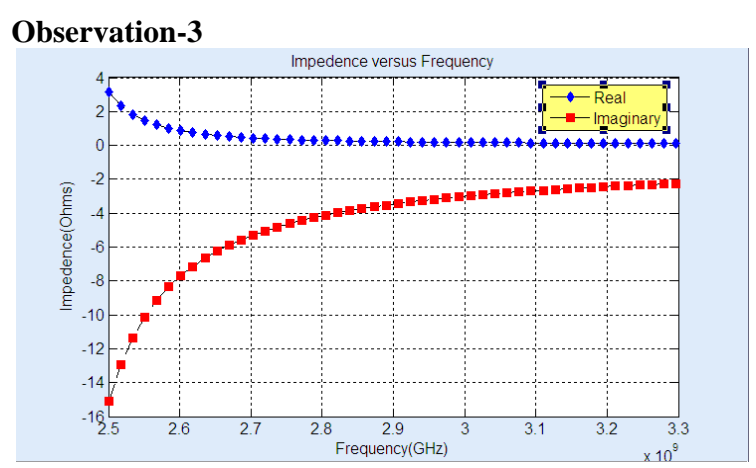

Variation of impedance vs frequency at $=3.78$

\section{Observation-4}

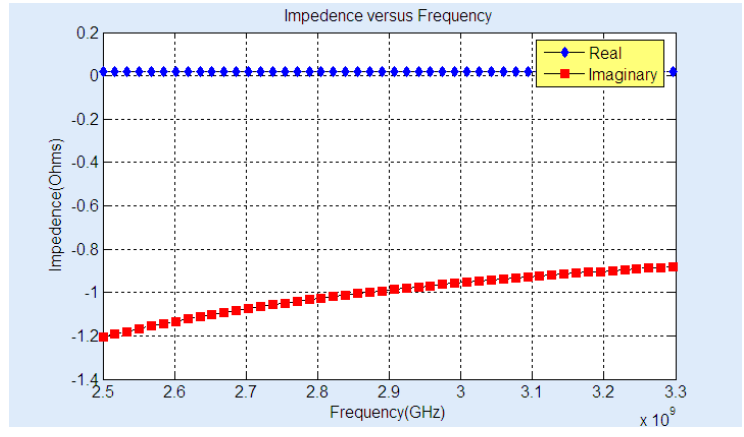

Variation of impedance vs frequency at $=9.4$

\section{Observation-5}

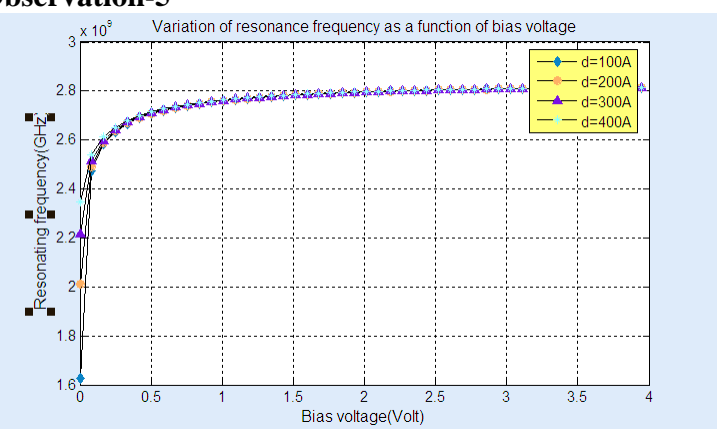

a). Keeping relative dielectric constant $=2.32$

Observation-6

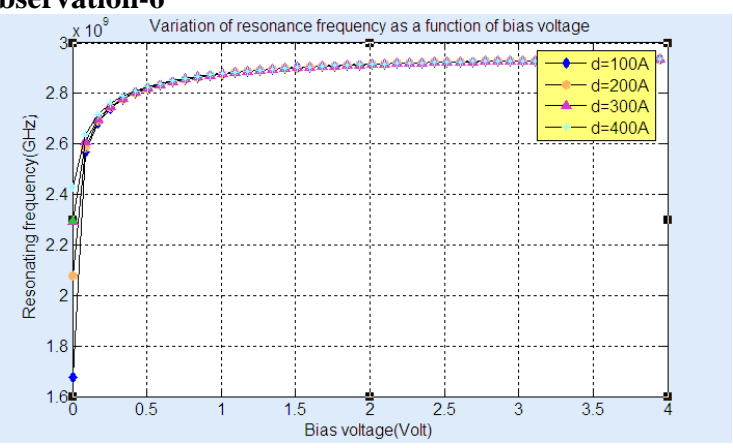

b). Keeping relative dielectric constant $=2.1$

\section{CONCLUSION \& FUTURE SCOPE}

In The initial stage, An antenna can be standard out by calculating some antenna parameters such as the input impedance, VSWR, reflection coefficient etc., first for unloaded circular patch microstrip antenna and then for the loaded antenna with MOS capacitor. The variation of these antennas parameters with respect to frequency has been graphically obtained and observed, which are shown in the figure.

The operating frequency of the unloaded antenna is $3.0085 \mathrm{GHz}$ at which the peak of the real part of the impedance is shown. At this the impedance is shown. At this the impedance is $49.97 \Omega$ but it can be seen that as the frequency is increasing the impedance first increase $s$ to its peak value then decreases to almost zero value. After loading, the input impedance decreases with frequency but peak remains the same at the operating frequency. The unloaded antenna has the only frequency at which it can work properly whereas the MOS capacitor loaded antenna has a range of frequencies to work without any malfunction, this feature is called tenability. The frequency 
may be varied by varying the reverse bias voltage of MOS capacitor.

Quality factor should be kept high to increase the selectivity of loaded antenna. As shown in the graph plotted, the quality factor increases up to resonance frequency[7] and then starts increasing whereas the Quality Factor is Quite low as in case of unloaded antenna.

The resonance frequencies are plotted as the function of bias voltage for various oxide thicknesses (1000A to 4000A) for TM10 mode. It is observed that the variation of the MOS capacitor is similar for all four oxide layers thickness. Larger variation in capacitance is observed when with bias voltage near zero bias, but it is very small at higher bias. The variation in resonance frequency in bias voltage for modified TM10 mode is inversely proportional to the oxide thickness. The maximum frequency agility is obtained for minimum oxide thickness.

\section{REFERENCES}

[1] Berardi Sensale-Rodriguez et.al, "Microstrip antenna analysis using the method of fundamental solutions", international journal of numerical modeling: electronic networks, devices and fields Int. J. Numer. Model. 2008; 21:563-581

[2] Ali Daliri, Amir Galehdar, Sabu John, Wayne Rowe \& Kamran Ghorbani "Circular Microstrip Patch Antenna Strain Sensor for Wireless Structural Health
Monitoring" 2010 Vol II WCE 2010, June 30 - July 2, 2010, London, U.K.

[3] Anil K Gautam and B R Vishvakarma, "MOS capacitor integrated microstrip antenna, Indian journal of radio \& space engg", Vol.35,Feb-2006, PP47-53.

[4] Sachin rai and D.K Srivastav "Analysis and design of circular shape microstrip antenna for wireless communication system", international conference (ACCTA-2010),VOL .1 Issue 2,3,4;2010,PP 331-337.

[5] Pasquale Dottaorato RF \& Microwave Design Engineer, "Design and Analysis of Rectangular microstrip patch antenna ", Microwave Journal Technical Library.

[6] W.K. Leverich, X.D, Wu and K.Chang, " New FET active notch antenna", Electronics Letters (UK), Vol.28, No.24,19th Nov. 1992,pp.2239-2240.

[7] Amir Mortazawi Bernard C. De Loach, "A NineMESFET Two-Dimensional Power-Combining Array Employing an Extended Resonance Technique",IEEE Microwave guided wave Lettters, VOL 3 No 7,Jul 1993,pp 214-216

[8] Hassani, H.R,Mirshekar-Syahkal D,“ Study of electromagnetically coupled stacked rectangular patch antennas", IEEE trans antenna and propag AP42(1994)1333 